\title{
EL DESARROLLO INSTITUCIONAL DEL ESTADO CENTRALIZADO EN VENEZUELA (1899-1935) Y SUS PROYECCIONES CONTEMPORANEAS
}

$321(87)$

por

Allan R. Brewer-Carias

Director del Instituto de Derecho Público UCV

SUMARIO: III. LA CONSOLIDACION DEL ESTADO CENTRALIZADO Y AUTOCRATICO (1899-1935): 4. LA CENTRALIZACIÓN FISCAL: LA ESTRUCTURA DE LA HACIENDA PÚblica (Continuación). 5. LA CENTRALIZACIÓN aDMINISTRATIVA: El DESARROllo DE la ADMINISTRACIÓN PÚBLICA. 6. LA CENTRALIZACIÓN LEGISLATIVA: EL PROGRESO DEL PENSAMIENTO JURÍDICO. - IV. EL ESTADO DEMOCRATICO CENTRALIZADO CONTEMPORANEO: 1 . LA CENTRALIZACIÓN EN EL PERfodo DE TRANSICIÓN A LA DEMOCRACIA 1936-1958. 2. LA FEDERACIÓN CENTRALIZADA A PARTIR DE 1961 Y EL PROCESO DEMOCRATIco. 3. El fortalecimiento DEL PODER NACIONAL Y EL DEBILITAMIENTO DE LOS Poderes estatales. 4. La tRansitoriedad DEL ANTIGUO RÉGIMEN MUNICIPAL.-V. EL RETO DE LA DESCENTRALIZACION PARA PERFECCIONAR LA DEMOCRACIA: EL NUEVO FEDERALISMO: 1. CENTRALIZACIÓN Y FEDERACIÓN. 2. LOS PROBLEMAS DEL CENTRALISMO: UN FENÓMENO UNIVERSAL. 3. El NUEVO FEDERALISMO.

En efecto, hasta 1915 rigió en Venezuela el sistema de «apartados», que consistía en destinar determinado ramo de rentas para 
cubrir con sus ingresos determinado ramo de gastos. Como ejemplos deben citarse el "fondo de abolición", derivado de la Ley de 1854 de abolición de la esclavitud, y que afectaba rentas, por ejemplo por destilación en alambiques, para destinarlas al pago de la indemnización que se debía a los antiguos propietarios de esclavos. El Servicio de Instrucción Pública, creado en 1870, funcionó hasta 1915 mediante la afectación al sostenimiento de escuelas del producto íntegro del impuesto nacional de estampillas, llamadas de escuela, que gravaba la circulación de títulos, a lo cual se agregó el producto del impuesto de estampillas de correo, de timbres y papel timbrado para cigarrillos y de derechos de registro.

El sistema de apartados, por ejemplo, afectó invariablemente determinadas rentas para atender las necesidades de crédito público, por lo que casi todos los empréstitos extranjeros suscritos desde 1823 contaron con cláusulas por las cuales se afectaban ramos de rentas para el pago del servicio de interés y amortización de los capitales. Por ejemplo, en el Protocolo de Wáshington de 1903, celebrado a raíz del bloqueo por Armadas europeas a los puertos venezolanos ese año, se comprometió para su cumplimiento el 30 por ciento de las entradas aduaneras de los puertos de La Guaira y Puerto Cabello, llegándose a estipular que si el Gobierno dejaba de cumplir dicha obligación, la Administración de las Aduanas se pondría a cargo de "funcionarios belgas» hasta que las deudas quedaran satisfechas. Asimismo, en el Convenio de París de 1905, respecto de las deudas inglesas y alemanas, se afectó el 60 por 100 de los derechos de aduana que se produjeran en las otras aduanas del país para pagarlas.

Con el principio de la Unidad del Tesoro desapareció el sistema de apartados y se concentró en el Tesoro la totalidad de los ingresos para con ello cubrir la totalidad de los gastos, con lo cual el Estado asumió el control directo de las rentas. Con posterioridad la ruptura del principio de la Unidad del Tesoro en la Ley Orgánica de Hacienda de 1928 se va a permitir sólo mediante la creación de los Institutos autónomos.

La reforma de 1918, por otra parte, incidió en el Presupuesto, el cual comenzó a ser un programa de gastos y de ingresos destinados a cubrirlos. Con anterioridad, y como consecuencia del sistema de apartados, la Ley del Presupuesto se limitaba a repartir el monto probable de las contribuciones que se votaban primero, para luego 
votar los gastos, los cuales quedaban limitados por el total de los ingresos probables. La consolidación del sistema presupuestario fue otro signo de la centralización fiscal del Estado.

\section{La CENTRALIZACIÓN ADMINISTRATIVA: EL DESARRollo DE LA AdMINISTRACión PÚBlica}

El proceso de centralización política y fiscal mediante la asunción de competencias por el nivel federal, y que se refleja en las sucesivas reformas constitucionales que amplían las materias que los Estados reservaron al Poder nacional, se materializó además en el establecimiento de un cada vez más poderoso aparato administrativo del Poder central integrado por los Ministerios como brazo efectivo del Estado centralizado.

En efecto, cuando Castro asume el poder estaba vigente la Ley de Ministerios de 1898, en la cual se establecieron los Despachos de Relaciones Interiores, Relaciones Exteriores, Crédito Público, Guerra y Marina e Instrucción Pública. Esos nueve Ministerios en la Ley de 1913 se reducen a los siete que habían salido de la Administración guzmancista: Relaciones Interiores, Relaciones Exteriores, Hacienda, Guerra y Marina, Fomento, Obras Públicas e Instrucción Pública, los cuales permanecen en igual número a pesar de que la Ley de Ministerios se reforma en seis ocasiones hasta 1929 (1915, $1920,1922,1926,1928$ y 1929).

En esas reformas sucesivamente fueron ampliándose las competencias ministeriales en los más variados órdenes. Sin embargo, sólo es en la reforma de 1931 que se crea un nuevo Ministerio, el de Salubridad y Agricultura y Cría, y sólo será en la reforma de 1936 que se crean los Ministerios de Sanidad y Asistencia Social, de Agricultura y Cría y de Comunicaciones, llegándose a nueve Despachos Ministeriales. Posteriormente, hasta 1976 es cuando se produce una reforma ministerial importante con la creación de nuevos Ministerios; sólo se crearán el Ministerio del Trabajo (1945), el Ministerio de Justicia y el Ministerio de Minas e Hidrocarburos (1950).

Debe señalarse además que en 1910 se había creado la Secretaría General de la Presidencia de la República, que recogió la Ley de Ministerios de 1926, como órgano de asistencia al Presidente para la conducción del Gobierno.

El Estado centralizado que emerge de la dictadura gomecista, por tanto, contaba con una Administración pública poderosa que 
sucesivamente fue configurándose en torno a los Ministerios, en los cuales ya se había formado una nueva burocracia, alentada por la estabilidad del régimen y por los mayores recursos fiscales provenientes de las actividades petroleras. Esta centralización administrativa provocó además con las reformas de la Hacienda pública la aparición por primera vez en nuestra estructura administrativa de la que hoy llamamos "la Administración descentralizada», con la creación en 1928 de dos Institutos autónomos: el Banco Agrícola y Pecuario y el Banco Obrero.

Después de 1935, sin duda, el proceso de centralismo administrativo en el nivel nacional se hará hasta la época contemporánea con estos instrumentos paradójicamente «descentralizados», pues será mediante los Institutos autónomos nacionales que el Poder nacional penetrará en todos los ámbitos nacionales avasallando las ya reducidas competencias estatales y municipales a costa, ciertamente, del progreso en muchos órdenes. Así, desde estas Instituciones. nacionales el Estado centralizado prestará el servicio de electrificación, teléfonos, abastecimiento de aguas, recolección de aguas negras e incluso recolección de basura, y construirá, por ejemplo, viviendas populares y las vías de comunicación.

\section{LA CENTRALIZACIÓN LEGISLATIVA: EL PROGRESO DEL PENSAMIENTO JURÍDICO}

Por último, el proceso de consolidación del Estado centralizado en las primeras tres décadas de este siglo se reflejó también en una importante obra de centralización legislativa, consecuencia, además, del progreso que tuvieron las ciencias jurídicas en nuestro país bajo el Gobierno autocrático de Gómez. Este desarrollo y centralización legislativa tuvo dos vertientes: en el ámbito de la codificación general y en materia legislativa especial.

En el campo de la codificación, durante la consolidación del Estado centralizado se produjeron importantes reformas en los Códigos fundamentales, que, dicho sea de paso, en nuestro sistema federal del siglo pasado se configuraban como una disidencia del mismo, en virtud de que siempre la legislación civil, criminal y procesal fue nacional o federal y nunca de la competencia estatal.

En la propia Constitución de 1864, al instaurarse el sistema federal, en las "Bases de la Unión de los Estados» éstos se comprometieron, entre otros aspectos, "a tener para todos ellos una misma 
legislación sustantiva, civil y criminal», lista a lo que se agregó en 1881 las «Leyes de Procedimiento Civil y Criminal».

En consecuencia, la codificación básica en Venezuela tuvo carácter nacional, y así en la segunda mitad del siglo pasado se dictaron los Códigos Civil, Penal y de Comercio. Esta labor global, a pesar de los esfuerzos previos incompletos, correspondió al Gobierno de Guzmán Blanco, lo que le permitió indicar a los legisladores en su mensaje al Congreso en 1873 lo siguiente: «Os entrego la República en perfecta paz, os presento un Código Civil, un Código Penal y un Código Mercantil que organizan nuestra vida civil». Y ello era cierto, pues hasta esa fecha habían regido en nuestro país todas las leyes españolas, que habían sido puestas en vigencia después del nacimiento de la República Autónoma en 1830.

En consecuencia, la labor codificadora nacional ya se había iniciado antes de la llegada de Castro al poder. Sin embargo, a partir de los inicios de su Gobierno, y luego durante el régimen gomecista, la codificación nacional se perfecciona, encargándose de la revisión de la legislación a los más destacados juristas del país, los cuales desarrollan una encomiable labor de modernización jurídica.

Durante las tres primeras décadas de este siglo en esta forma el Código Civil se reforma en 1916 y 1922; el Código Penal en 1904, 1912, 1915 y 1926; el Código de Comercio en 1904 y 1919; el Código de Procedimiento Civil en 1904 y 1916, y el Código de Enjuiciamiento Criminal en 1904, 1911, 1915 y 1926. En esta tarea, como se dijo, intervinieron los mejores juristas de la época, y en ese período se produjo un importante desarrollo del pensamiento jurídico, teniendo como resultado una influyente bibliografía y la aparición tanto en Caracas como en el interior de reputadas revistas jurídicas.

Como resultado de ese proceso, lo cierto es que la legislación penal vigente sigue siendo básicamente la concebida en el Código Penal de 1926, con ligeras reformas; el Código de Procedimiento Civil vigente es aún el de 1916; el Código de Comercio de 1919, que había refundido las Leyes de Bolsa de 1917, la Ley de Sociedades Cooperativas de 1917 y la Ley sobre Actividades de Sociedades Extranjeras en Venezuela de 1918 sólo sufrió ligeras reformas en 1956, y el Código de Enjuiciamiento Criminal de 1916 configurará el actual proceso penal. Sólo el Código Civil sufrirá modificaciones importantes después de 1935, en 1942 y recientemente en 1982.

Pero en el campo de la legislación especial el proceso de centra- 
lización legislativa en el Estado nacional fue más notorio y contrasta con la situación del sistema federal del siglo pasado.

En efecto, después de la consolidación definitiva del Estado federal en 1864, salvo en materia de Códigos nacionales y alguna que otra materia que se reservaba a nivel federal, como el régimen de la nacionalidad, la autonomía de los Estados que conformaron la Federación implicó que éstos asumieran la competencia legislativa para dictar sus propias leyes y, por supuesto, administrar su propia justicia. La realidad del federalismo del siglo asado resulta así además del examen de la legislación de las entidades federales, elaboradas, por lo demás, por las élites ilustradas de cada Región. Entre esa legislación destacan los Códigos de Policía de cada Estado, que regularon su actividad administrativa y que constituyeron no sólo verdaderos monumentos jurídicos de la legislación venezolana del siglo pasado, sino antecedentes evidentes de la mayoría de los aspectos de la legislación especial de este siglo.

A partir de 1864, por tanto, los Estados asumieron el papel de promulgar la legislación especial básica del país, sustituyendo la labor antes desarrollada por las ordenanzas municipales, y es precisamente en los Códigos de Policía que comienza a legislarse sobre sanidad, defensa forestal, tránsito, urbanismo, régimen del trabajo, aprovechamiento de las aguas y, en general, sobre los servicios públicos; y en todos ellos con una sorprendente uniformidad.

El proceso de centralización de competencias en el nivel federal a costa de las competencias de los Estados en las primeras décadas de este siglo produjo por tanto un proceso de centralización legislativa que se evidencia en el inicio o consolidación de una legislación nacional, dictada en materias antaño reguladas en los viejos Códigos de Policía de los Estados. En el período de Castro y Gómez, por tanto, surge la legislación fundamental en todos los órdenes por el vaciamiento de competencias estatales, transfiriéndose además muchas de dichas competencias a los Distritos autónomos establecidos a partir de 1904. Esto se regulariza en la Constitución de 1925, dando origen, en consecuencia, a nuevas Ordenanzas de Policía, dictadas entonces a nivel de las Municipalidades, muchas de las cuales continúan en su concepción básica aún vigentes.

De nuevo aquí apreciamos las consecuencias del centralismo como reacción contra el nivel intermedio de los Estados, lo que se materializa en el reforzamiento de un nivel municipal a nivel de 
Distritos, lo suficientemente alejados, sin embargo, de las comunidades, de manera de impedir el desarrollo político propio de éstas.

En materia de legislación especial, en todo caso es en las primeras décadas de este siglo que se comienzan a regular coherentemente los aspectos fundamentales de la vida del país como reflejo del centralismo. Dejando aparte los cuerpos normativos en materia de organización administrativa, militar, tributaria y fiscal, a los cuales hemos hecho referencia, en este período, entre las más importantes, se producen las siguientes legislaciones básicas, en las cuales están los antecedentes de muchas de las normas que hoy nos rigen:

En materia de actividades crediticias, si bien las primeras regulaciones sobre Bancos datan de 1860 (Ley de Bancos de Depósitos y Circulación), de 1894 (Ley de Bancos Hipotecarios) y de 1895 (Ley de Bancos), la Ley de Bancos se va a reformar en 1903, 1904, 1910, 1911, 1913, 1918, 1926 y 1935, dictándose además la Ley de Cédulas Hipotecarias en 1916. En 1928 se dicta además la primera Ley sobre Inspección y Vigilancia de las Empresas de Seguros.

La legislación relativa a la educación se va a redactar en su concepción moderna en 1915 y 1924. Antes de 1915 existía el Código de Instrucción Pública de 1897 (con reformas en 1904, 1905, 1910 y 1912), pero en 1915 se promulgan, en sustitución del Código, la Ley Orgánica de Instrucción, la Ley de Instrucción Obligatoria, la Ley de Inspección Oficial de la Instrucción, la Ley de Instrucción Primaria Pública, la Ley de Instrucción Secundaria Pública, la Ley de Instrucción Especial, la Ley de Instrucción Normalista Pública, la Ley de Instrucción Superior y la Ley de Certificados y Títulos Oficiales, las cuales sufren reformas importantes en 1926. Allí, sin duda, están los antecedentes, pero con una técnica legislativa superior, de la actual Ley Orgánica de Educación. En 1904, además, se crea la Academia Nacional de Medicina, en 1915 la Academia de Ciencias Políticas y Sociales y en 1917 la Academia de Ciencias Físicas, Matemáticas y Naturales.

En materia de sanidad, en 1912 se dicta la primera Ley de Sanidad Nacional, con reformas posteriores en 1919, 1920 y 1923, y que culmina con la Ley vigente de 1942; además, en 1912 se dicta la Ley de Vacunas, en 1913 la Ley de Defensa Sanitaria Vegetal y Animal, en 1915 la Ley de Ejercicio de la Farmacia y en 1930 la Ley de Narcóticos.

En el campo laboral, en 1928 se dicta la primera Ley del Traba- 
jo, reformada luego en 1936, en la cual está el antecedente inmediato de la actual legislación en la materia.

En el área de protección de los recursos naturales renovables, en 1910 se dicta la Ley de Bosques, y luego en 1915 la Ley de Montes y Aguas, con reformas en 1921. En 1931 se promulga la Ley de Bosques y Aguas, reformada en 1935, antecedente inmediato de la vigente Ley Forestal de Suelos y Aguas, pero dicho sea de paso, aquí también con una técnica legislativa muy superior a la Ley actual.

En el campo de los recursos naturales no renovables, el viejo Código de Minas, cuyo origen se sitúa en 1845, se sustituye en 1915 por la Ley de Minas, que luego se reforma, sucesivamente, conforme avanza la explotación del subsuelo en 1918, 1920, 1922, 1925, 1928, 1934 y 1936, proceso que originará posteriormente la Ley de Hidrocarburos de 1936, reformada en 1938 y 1942, y que configura básicamente el cuerpo normativo vigente. Esta Ley, sin embargo, tuvo sus antecedentes en la Ley de Hidrocarburos y demás minerales combustibles de 1920, que sustituyó los viejos Reglamentos de carbón, petróleo y sustancias similares de 1904, 1914 y 1918.

Por supuesto, es en este período de principios de siglo que los avances de las comunicaciones hacen aparecer nuevas necesidades de regulación legal. Por ello, en 1920 se dicta la Ley de Aviación; en 1915 se había comenzado a regular el tráfico por carreteras, que concluye luego en la Ley de Tránsito Terrestre de 1926; en 1912 se dicta la Ley de Concesiones Ferrocarrileras, sustitutiva de una regulación dispersa del siglo pasado; en 1909 se dictó la Ley de Telégrafos y Teléfonos, sustituyendo las viejas leyes orgánicas del Telégrafo Nacional de 1899, y en 1921 se regula la radiotelegrafía.

A los efectos del proceso de electrificación, se dicta la Ley de Servidumbre de Conductores Eléctricos de 1928, aún vigente. En 1909 se promulga la Ley de Expropiación por Causa de Utilidad Pública y Social, sustitutiva de viejos decretos legislativos del siglo pasado sobre restricciones a la propiedad; y para regular las obras públicas, en ese mismo año se dicta el Decreto Reglamentario de Obras Públicas que aún no hemos logrado sustituir ni actualizar en nuestro país. Estos instrumentos facilitaron el desarrollo de las comunicaciones mediante la construcción de carreteras, lo que condujo a la integración física del país. 


\section{EL ESTADO DEMOCRATICO CENTRALIZADO CONTEMPORANEO}

El Estado que emerge del período $1899-1935$ fue, por tanto, un Estado centralizado, y aun cuando posteriormente, hasta la actualidad, los textos constitucionales conservaron la forma o ropaje federal, el desarrollo institucional posterior fue, y ha sido, de acentuación del centralismo en todos los órdenes, tanto en el período de transición a la democracia de 1936 a 1958 como en el período democrático contemporáneo.

\section{La CENTRALIZACión EN El PERÍodo dE TRANSICIÓN A LA DEMOCRACIA 1936-1958}

El Estado venezolano en 1936, por tanto, no era ni la sombra del que había sido fácil presa del Dictador: no sólo aparecía ahora integrado políticamente, sino que, debido a los recursos fiscales provenientes del petróleo, aparecía como una Entidad de un enorme poder económico. Como hemos señalado, la política de la Dictadura, siguiendo la orientación de los gobiernos del último cuarto del siglo XIX, había sido progresivamente centralista, de manera que en las sucesivas reformas constitucionales se le fueron quitando o limitando poderes a los Entes locales: los Estados y Municipalidades. A pesar de la forma "federal», el Estado de 1936 era un Estado casi completamente centralizado, y si bien la justicia permanecía en cierta forma en poder de los Estados, la Constitución de 1945 dio el golpe de gracia a la descentralización al nacionalizarse las actividades judiciales.

Bajo la vigencia de la Constitución de 1936 se inició, en todo caso, el proceso de transformación social del país, a cuyo efecto el Texto constitucional no sólo comenzó a regular los derechos sociales, en particular, como se dijo, los de carácter laboral, sino que dio un vuelco definitivo en la evolución de dos de las libertades que constituyen el pilar de la organización socioeconómico-política del Estado moderno: la propiedad y la libertad económica, lo cual continuó en el Texto de 1945.

Después de la Revolución de octubre de 1945, y como producto de una Asamblea constituyente electa por primera vez mediante sufragio universal, directo y secreto, se sancionó la Constitución de 
1947, la cual dividió territorialmente el Estado en el de los Estados, el del Distrito federal, el de los Territorios federales y el de las Dependencias federales, estas últimas formadas por las islas del mar Caribe, de acuerdo a la figura creada por la Constitución de 1925. El territorio de los Estados, siguiendo la orientación de la de 1904, se dividió en "Distritos municipales, y el de éstos, a su vez, en Municipios». En esta forma el Poder público se distribuyó «entre el Poder municipal, el de los Estados y el nacional», correspondiendo, sin embargo, el ejercicio del primero a Concejos municipales ubicados en cada Distrito de los Estados y no en los Municipios. Se inició así la confusión que aún perdura actualmente entre la Municipalidad (Distrito municipal) y el Concejo municipal (órgano que representa a la Municipalidad), a quien se atribuyó el ejercicio del Poder municipal.

En este esquema de distribución vertical del Poder, la Constitución de 1947, si bien conservó el nombre de Estados Unidos de Venezuela, eliminó el Título inicial que tenían las Constituciones desde 1864, relativo a las "Bases de la Unión», y lo sustituyó por un extenso título relativo al Poder de los Estados, en el cual aún se conservaban competencias sustantivas de éstos en materia de desarrollo económico y físico. En cuanto al Poder municipal, la Constitución de 1947 destinó también un desusado y extenso título a su regulación con detalle respecto del ámbito de la autonomía «de los Concejos municipales» y de la competencia del Poder municipal, la cual también tenía un contenido más amplio que el actual, aun cuando con previsión expresa, en muchos casos, respecto de que esa competencia debía ejercerse "con sujeción a las Leyes y Reglamentos nacionales", con lo cual se limitaba sustancialmente la referida autonomía del Poder municipal.

En cuanto al Poder nacional, al eliminarse el título de las «Bases de la Unión", se estableció en el texto de 1947 un Título especial dedicado al mismo, en el cual se enumeró su competencia en el estilo que ahora está en el artículo 136 del Texto constitucional de 1961. Se previó, en consecuencia, en virtud de la tendencia centralista que este texto conlleva, la posibilidad de que las Cámaras legislativas descentralizaren competencias nacionales a los Estados y Municipalidades, lo cual recoge la Constitución de 1961 en su artículo 137. Se reguló detalladamente lo relativo a las relaciones internacionales, a las Fuerzas Armadas nacionales y a la Hacienda pública nacional, de manera muy diferente a la tradición constitucio- 
nal precedente, y en cuanto al Poder nacional, éste, dividido en Poder legislatıvo, ejecutivo y judicial, fue objeto de una regulación orgánica detallada, que siguió muy de cerca la Constitución vigente.

Después del inicio de la Dictadura militar a partir de 1948, se sancionó la Constitución de 1953, la cual, aun cuando tuvo como modelo el texto de 1945, resultó mucho más conservador política, social y económicamente hablando; mucho más centralista, y de contenido formal bastante simplista, si se compara su redacción con la Constitución de 1947.

Esta Constitución, en cuanto a la forma del Estado, formalmente estableció el mismo principio de distribución vertical del Poder público formulado en los textos precedentes a partir de 1925 «entre el Poder municipal, el de los Estados y el nacional», y destinó capítulos específicos a regular a los Estados, a las Municipalidades, que continuaron existiendo a nivel de los Distritos, y al Poder nacional. Sin embargo, cambió radicalmente el principio básico del Federalismo de 1864, que habían repetido todas las Constituciones precedentes hasta 1947, y que colocaba el poder residual en los Estados. La Constitución de 1947, por ejemplo, en esa tendencia, atribuyó a los Estados competencia en «todo lo no reservado expresamente por esta Constitución a las Leyes, a la Nación o Municipalidades», y si bien se apartó de la tradición constitucional que regulaba este poder residual como una materia de reserva constitucional, permitiendo, en cambio, que por Ley se atribuyeran competencias a nivel nacional, el principio del poder residual de los Estados siempre estuvo vigente.

La Constitución de 1953, al contrario, cambió el nivel residual y se lo atribuyó al Poder nacional, al establecer como competencia de éste «toda otra materia que la presente Constitución no atribuya a los otros Poderes», con lo cual, formalmente, se acabó con uno de los últimos vestigios del Federalismo. La Constitución de 1953, además, abandonó la denominación de la Nación como «Estados Unidos de Venezuela» que el Texto de 1864 había impuesto y se adoptó la denominación contemporánea de la República de Venezuela.

El proceso de centralización del Estado, por tanto, continuó inexorablemente a partir de la muerte de Gómez, y se reforzó en todos sus aspectos en el período de transición hacia la democracia que transcurre desde 1936 hasta 1958 y condicionó la configuración del Estado democrático contemporáneo a partir de 1958. 
2. LA FEDERación Centralizada A PARTIR DE 1961 Y EL PROCESO DEMOCRÁTICO

Puede decirse, por tanto, que el signo más característico del Estado actual es el centralismo, acentuado por la Constitución de 1961, esquema que por lo demás formó parte del Proyecto político de implantación de la democracia que se formuló a partir de 1958, en el Pacto de Punto Fijo.

Este Estado democrático centralizado contemporáneo, por supuesto, como se ha visto, no es otra cosa que el resultado de un proceso evolutivo de centralización del Estado, en el cual, si se quiere, ganan las fuerzas de integración frente a las de disgregación en la estructuración política de la sociedad venezolana. Ese proceso evolutivo, como hemos visto, tiene su origen en todos los problemas del caudillismo, del localismo y del regionalismo que durante el siglo pasado tuvieron tanta repercusión en la vida política venezolana, y que se magnificaron, además, en la literatura autocrática y centralista de los teóricos políticos del régimen gomecista. Por ello, todavía en nuestra política contemporánea, cuando se habla de $\mathrm{Fe}$ deración, algunos inconscientemente evocan las guerras federales; y cuando se busca otorgarle mayor autonomía a las Entidades político-territoriales, a los Estados de la Federación, otros piensan en la posibilidad del separatismo. Son reminiscencias del siglo pasado, cuya vida política quedó traumatizada, en nombre del Federalismo, por el caudillismo; condicionada por la prédica centralista de comienzos de este siglo. De allí que la opción Centralismo-Federación aparece en la propia Constitución de 1961.

En efecto, la Exposición de Motivos de la Constitución dedica una parte muy extensa al tratamiento de la forma del Estado venezolano, y particularmente al problema de su forma federal. La Exposición de Motivos, inclusive, recoge la polémica que surgió en la Comisión bicameral desde las primeras reuniones, la cual se planteó en los dos extremos del pensamiento sobre el problema federal: algunos que plantearon la eliminación de la Federación, definitivamente, como forma del Estado venezolano; y otros, al contrario, que plantearon la tesis de reforzar la Federación, como instrumento descentralizador.

En esta forma, la Exposición de Motivos de la Constitución dice lo siguiente: «La Comisión se abocó al estudio de si resultaba con- 
veniente mantener la forma federal del Estado venezolano. La vieja polémica de centralistas y federalistas pudo empezar a revivirse en nuestras primeras reuniones, que habrían tomado un curso de discusiones infecundas, como lo ha sido en gran parte esta polémica a lo largo de nuestra historia...»

Sin embargo, dentro del espíritu unitario que orientó los trabajos de la Comisión, la Exposición de Motivos reconoció que: «Los trabajos se dirigieron hacia el encuentro de una fórmula capaz de evitar lo árido de las contradicciones y ofrecer una solución cónsona con nuestros antecedentes y con la estructura real del Estado».

Con ello se estaba diciendo que partiendo del proceso político precedente con tendencia centralista, sobre todo durante este siglo, la fórmula a adoptar debía ser cónsona con la estructura real del Estado venezolano, el cual, sin duda, a comienzos de los años sesenta, era un Estado centralizado. Y agrega la Exposición de Motivos: "Quienes pensaron en la eliminación de la forma federal creyeron que era preferible reemplazar la estructura de la Federación por un sistema de descentralización administrativa o de autonomías progresivas que funcionarían más de acuerdo con la realidad venezolana; quienes se pronunciaron por el mantenimiento de la forma federal del Estado arguyeron, entre otros motivos, los de origen histórico, que hicieron arraigar el movimiento federalista en el sentimiento nacional».

De este resumen de las dos posiciones se confirma que la estructura real del Estado era la centralista, y que para no caer en contradicciones estableciendo un real Estado federal, había que regular una forma de Estado que, sin dejar de ser federal, fuera centralista. Y no otra cosa se hizo: se reconocía que no había descentralización política en el sistema y que lo federal era una cuestión de tradición histórica. Las dos posiciones, sin embargo, eran inaceptables: si había una forma federal tradicional, como forma ideal de descentralización, lo lógico era aprovechar esa forma y darle contenido y no pensar en eliminarla para estructurar una forma nueva de descentralización, y, por supuesto, mantener la Federación sólo por razones históricas, sin contenido descentralizador, tampoco tenía sentido.

El argumento de la Comisión, en todo caso, para consolidar la Federación centralizada que está en la Constitución fue el siguiente: «La Comisión comenzó por reconocer que el sentimiento federal, las consecuencias del federalismo en el sentido de la organización social y el nombre mismo de la Federación, constituyen un hecho 
cumplido y hondamente enraizado en la conciencia de los venezolanos. Por otra parte, estimó que, a pesar de no haberse realizado efectivamente, la Federación sigue siendo en el espíritu de la mayoría un desiderátum hacia el cual debe tender la organización de la República».

De esto último resulta una declaración importante: se consideró la Federación como un desiderátum hacia el cual debe tender la organización de la República. Es decir, se reconoció que la forma del Estado no es propiamente la de una Federación, sino que debíamos tender a ser Federación.

Y agrega la Exposición de Motivos: «Pensó también la Comisión que la semántica en la vida política y jurídica no tiene contenido inmutable. Los vocablos se entienden no sólo por su significación literal, sino por el ambiente histórico y las circunstancias en las cuales se han realizado los valores que representan. La palabra 'democracia' en Francia es inseparable del establecimiento del régimen republicano y de la abolición de la monarquía; la palabra 'democracia' en Inglaterra se armoniza con la subsistencia de la monarquía británica. Los vocablos tienen una acepción propia, que es la que le atribuyen los hechos históricos».

Partiendo de esa premisa, concluye la Exposición de Motivos: «Federación», en unas partes, significó la integración de unidades dispersas para formar un todo armónico; «Federación", en los países de América latina, significó a veces la disgregación de una unidad en comunidades locales. Pero "Federación» en Venezuela, propiamente hablando, representa un sistema peculiar de vida, un conjunto de valores y de sentimientos que el Constituyente está en el deber de respetar, en la medida en que los intereses del pueblo lo permitan. Por ello se adoptó la definición con que se abre el primer título: «La República de Venezuela es un Estado federal en los términos establecidos por esta Constitución. Es decir, que es una Federación en la medida y forma peculiar en que esta idea ha sido vivida dentro de la sociedad venezolana».

Por supuesto, con ello no se está diciendo absolutamente nada, salvo que se trata de una Federación en un Estado centralista. Se sigue, así, una tradición contradictoria: mantener la forma federal y el espíritu federalista que ha acompañado a toda la historia republicana, por una parte; y por la otra, reaccionar contra la Federación, como forma de disgregación, y consolidar un Estado centralizado, que es el que venía estableciéndose como reacción frente a 
lo que fue el localismo, el caudillismo y los problemas que ello produjo con las guerras federales y todos los conflictos internos derivados de autonomía local, hasta principios de siglo. Por ello se se llega a esa solución de compromiso contradictoria: "Estado federal en los términos consagrados en la Constitución». Es decir, una Federación centralizada.

Pero aparte de que ésta haya sido la culminación de un proceso histórico evolutivo, sin duda, pensamos que la opción que los Constituyentes de 1961 hicieron por un Estado federal centralizado, con tendencia, como desiderátum, hacia la descentralización, fue también una opción provocada por la exigencia política del mantenimiento del sistema democrático.

En efecto, así como se estableció un sistema de democracia de partidos como opción política para mantener el sistema democrático, así también se optó por una forma de Estado centralizado como la mejor garantía para mantener ese sistema democrático. Ciertamente, no hubiera sido fácil mantener el sistema democrático en el momento naciente de la República democrática si se hubiera dado mucha autonomía y libertad a las diversas comunidades políticoterritoriales de la República: los Estados y Municipios. Por tanto, la opción por el Estado centralizado con forma federal, aparte de ser producto de una evolución histórica, fue el producto de una voluntad del Constituyente de mantener el sistema democrático, considerando que la mejor forma de mantenerlo era a través de un sistema de democracia de partidos que operara en un aparato estatal centralizado, controlable desde el centro. Porque, sin duda, todo proceso descentralizador implicaría disminución de los poderes centrales de control.

Ahora bien, este Estado centralizado, establecido como reacción contra el federalismo, se manifiesta básicamente en dos aspectos en el momento actual: en el fortalecimiento del Poder nacional y el consecuente debilitamiento de los Poderes estatales; y en la transitoriedad del Régimen municipal.

\section{El fortalecimiento del Poder nacional y el debilitamiento DE LOS Poderes estatales}

El primer efecto de la reacción contra el federalismo está en el fortalecimiento del Poder nacional y en el debilitamiento de los Poderes de los Estados, lo cual, por supuesto, también es el resultado 
de un proceso evolutivo, que se manifiesta básicamente en el sistema de repartición de competencias entre los niveles territoriales nacionales y estatales, como consecuencia del sistema de distribución vertical del Poder público.

En efecto, si se analiza el artículo 136 de la Constitución vigente de 1961, relativo a las competencias del Poder nacional, se evidencia una ampliación de las competencias nacionales que, materialmente, provoca que el Poder nacional tenga que ver con todo lo que sucede en el país. Lo que queda en poder de los Entes territoriales locales es, realmente, un residuo sin mayor importancia. Por supuesto, esto es producto de una evolución desarrollada durante décadas, por lo que no podemos decir que el fortalecimiento del Poder nacional frente a los Poderes de los Estados federados o al Poder municipal sea producto de este texto, lo cual, sin embargo, no impide afirmar que el esquema no haya respondido también a necesidades del momento. Por ello, sin duda, el fortalecimiento del Poder nacional no fue un azar, sino que responde a la búsqueda por consolidar un Estado centralizado. Y sobre esto también se ocupa la Exposición de Motivos de la Constitución, cuando comenta el capítulo II, dedicado al Poder nacional. En efecto, al referirse a la competencia del Poder nacional, constata que el tema "ha sido uno de los más desordenadamente redactados en la Carta fundamental. La adición sucesiva en cada reforma constitucional, que se ha hecho de nuevas y mayores atribuciones al Poder nacional, no ha sido siempre acompañada por un estudio técnico y una redacción apropiada de las correspondientes originales». Y agrega al comentar el artículo 136 de la Constitución: "... la redacción que ofrecemos no pretende presentarse como perfecta. Tenemos conciencia de su imperfección, y creemos que puede mejorarse todavía. Sin embargo, creemos que su redacción, el orden en que se expresan las materias y la utilización de vocablos más precisos para distinguir aquellas materias que en su integridad corresponden al Poder nacional, de aquella en que éste sólo dicta normas y regulaciones, nos hace pensar que el texto del proyecto está muy mejorado en relación a los antecedentes...»

Una de las cuestiones que más preocupó a la Comisión bicameral fue el relativo al sistema de distribución de competencias entre el Poder nacional y los Estados federados, es decir, el de la competencia residual. "Según el pacto federal —continúa la Exposición de Motivos- los Estados sólo delegan en el Poder nacional aquellas materias que expresamente se enumeran, y que después de la Cons- 
titución de 1864 aparecieron bajo el concepto de reservas a la competencia federal. Era la norma básica la de que los Estados conservan en toda su plenitud la soberanía no delegada en la Constitución... En las Constituciones recientes se utilizaba un sistema distinto. La de 1947 atribuía al Poder estatal toda materia que la Constitución no atribuyera expresamente a otro poder. Esta norma tenía ya antecedentes directos, y por no citar sino los más inmediatos recordaremos que la Constitución de 1936, reformada en 1945, expresaba en el último ordinal del artículo, sobre la materia reservada por los Estados a la competencia del Poder federal: 'Por último, cualquiera otra materia que la presente Constitución no atribuya a alguno de los Poderes que integran el Gobierno federal y que no hayan sido enunciados en este artículo...'; aun cuando es de señalar que todavía entonces se mantenía el precepto federativo de la conservación por los Estados de la soberanía no delegada en la Constitución. La Constitución de 1953 agravó el proceso de centralización y suprimió la precisión descentralizadora que el Constituyente de 1947 estableció».

Constatada, por tanto, la evolución del proceso centralizador que culmina en 1953, donde se invierte, como hemos dicho, la competencia residual, atribuyéndosela al Poder nacional y no a la de los Estados, la Comisión bicameral concluye señalando lo siguiente: «... El sistema que después de determinado análisis hemos adoptado en nuestro Proyecto es el siguiente: a) Por una parte, conservamos el principio federal, según el cual es de la competencia de cada Estado: 'Todo lo que no corresponda de conformidad con esta Constitución a la competencia nacional o municipal'. Con ello la competencia residual se atribuye fundamentalmente a las Entidades federativas. b) Se aclara, sin embargo, que pueda haber materias no previstas que, por su índole o naturaleza, deben corresponder al Poder nacional. Pensamos que esto podría suceder, por ejemplo, con las derivaciones de la energía nuclear o con otros asuntos que el desarrollo de la técnica $u$ otras circunstancias puedan hacer aparecer y que, por su misma índole, no corresponden a la competencia residual de los Estados. De esta manera hemos creído conciliar el derecho inmanente de las Entidades que integran la Federación con los supremo intereses de la República». Y luego concluye la Exposición: «Se conserva en el Proyecto una acertada previsión de la Carta de 1947: la de que el Congreso, por el voto de las 2/3 partes de sus miembros, podrá atribuir a los Estados o a los Municipios 
determinadas materias de la competencia nacional, a fin de promover la descentralización administrativa...»

Esta fórmula constitucional centro-federal que adopta la Constitución de 1961 sigue, sin duda, el mismo sistema conciliatorio adoptado para el establecimiento de otras instituciones en el Texto fundamental: permite su desarrollo en la dirección que quiera la conducción política. Así, en principio, es un esquema federal con competencias residuales en los Estados, pero con una competencia nacional amplísima y ampliable cuando ello sea así por su índole o naturaleza, que permite centralizar materialmente todo. El esquema centralista que resulta, sin embargo, puede mitigarse estableciéndose la posibilidad expresa de que el Poder nacional pueda descentralizar.

En el sistema de distribución de competencias adoptado en la distribución vertical del Poder entre los niveles nacional, estatal y municipal, se insiste, la competencia residual se atribuye formalmente a los Estados, pero deliberadamente debilitada, pues se enumeran tantas competencias en el artículo 136 de la Constitución a favor del Poder nacional, y en el artículo 30 de la Constitución, a favor de los Municipios, que el residuo, como tal, es casi inexistente, y sólo un esfuerzo imaginativo puede contribuir a identificar materias concurrentes o residuales a favor de la competencia de los Estados.

En definitiva, la Constitución ha establecido una forma de Estado centralizado con membrete federal, precisa y contradictoriamente como reacción frente al federalismo, y que se caracteriza por el fortalecimiento del Poder nacional en el artículo 136, al definirse las competencias nacionales; por el debilitamiento de los Poderes estatales por la inocuidad de los poderes residuales, y por la ausencia de recursos financieros de los Estados y su dependencia frente a los recursos fiscales que provienen del Poder nacional.

En este sentido, hemos destacado cómo junto con el proceso de nacionalización o centralización de competencias, y el consecuente vaciamiento de competencias de los Estados, paralelamente se desarrolló un proceso de minimización de competencias tributarias de los Estados, eliminándoles materialmente todo poder tributario y compensándoles esta situación con el establecimiento de un sistema de retribución o de "devolución" nacional a los Estados de recursos financieros, que adquirió el nombre de "Situado constitucional».

El Situado constitucional, así, no es otra cosa que una especie 
de devolución por el Poder central, a los Estados, de recursos financieros, en compensación por los poderes tributarios que se han centralizado, y se configura como una partida anual en la Ley de Presupuesto Nacional, por un monto equivalente al 15 por 100 de los ingresos ordinarios, que debe distribuirse entre los Estados, el Distrito federal y los Territorios federales. En la actualidad este es el ingreso fundamental de los Estados.

Pero, además, la centralización progresiva de competencias también ha comprendido los bienes de los Estados, y progresivamente: las Constituciones han atribuido su administración al Poder nacional. Por ello, el ordinal $10 \mathrm{del}$ artículo 136 atribuye al Poder nacional competencia respecto del "régimen y administración de las minas e hidrocarburos, salinas, tierras baldías y ostrales de perlas", con lo cual, materialmente, se le quita a los Estados la administración de sus bienes, como una muestra más del centralismo. Sin embargo, para mitigarlo, el propio Texto constitucional trae una previsión expresa, aun cuando no desarrollada hasta el presente, según la cual «la Ley establecerá un sistema de asignaciones económicas. especiales en beneficio de los Estados en cuyo territorio se encuentren situados los bienes que se mencionan en este ordinal...», es decir, las minas e hidrocarburos, salinas, tierras baldías y ostrales. de perlas, "sin perjuicio de que también puedan establecerse asignaciones especiales en beneficio de otros Estados». En este caso las. asignaciones estarían sujetas a las normas de coordinación previstas en el artículo 229 de la Constitución, es decir, a las previstas para la inversión del Situado constitucional en coordinación con planes administrativos nacionales.

De nuevo, en estas normas se observa el matiz conciliador de posiciones de la Constitución: centraliza la administración de los bienes de los Estados; en compensación prevé la posibilidad de que se les atribuyan asignaciones económicas especiales, pero su inversión debe coordinarse con el Poder nacional, por lo que, de nuevo, se abre la posibilidad de centralizar.

En todo caso, insistimos, es evidente que este sistema centralizado que prevé la Constitución tuvo una motivación política concreta, aparte de ser el resultado de un proceso evolutivo: consolidar el régimen democrático de partidos, minimizando el desarrollo de poderes políticos locales que en el naciente Estado pudieran conspirar contra el mantenimiento del sistema democrático. Posiblemente, si se establece una forma de Estado descentralizado en 1960, no 
se hubieran podido controlar las fuerzas centrífugas del proceso político, y hubiera sido más difícil consolidar el sistema democrático. Transcurridos veintisiete años de democracia, y consolidada ésta, el perfeccionamiento de la misma permite ahora evaluar el esquema de Estado centralizado y plantear las exigencias de descentralización política contemporánea.

\section{LA TRANSITORIEDAD DEL ANTIGUO RÉGIMEN MUNICIPAL}

El otro signo del esquema de Estado centralizado que previó la Constitución de 1961, sin duda, fue la transitoriedad del antiguo Régimen municipal.

En efecto, si hemos dicho que en el Texto constitucional se evidencia una tendencia centralizadora y una reacción contra la descentralización y las autonomías locales, evidentemente que es contradictorio con ello el Régimen municipal que regula el capítulo IV del Título I del texto, donde se establece un Municipio ideal, con amplia autonomía local, como ejemplo de descentralización políti$\mathrm{ca}$, en el cual se le otorgan amplios poderes, tanto en las materias propias de la Vida local como en la gestión de los intereses peculiares de la Entidad, con importantes poderes tributarios.

La aplicación inmediata de este Régimen municipal, se insiste, hubiera sido completamente contradictorio con el esquema de Estado centralizado que se buscaba establecer, por lo que deliberadamente el Constituyente dejó en suspenso dicho Régimen, a través de una Disposición transitoria, en la cual se ordenó dejar en vigencia el Régimen anterior, consolidado bajo la Constitución de 1953, hasta tanto no se desarrollasen legalmente las normas constitucionales. De nuevo aquí se observa el sistema del Constituyente de prever y no prever: se instituye un Régimen municipal ideal, pero se impide su aplicación por una norma transitoria. Así, la Disposición transitoria primera de la Constitución estableció que: «... Mientras se dicten las Leyes previstas en el capítulo IV del Título I de la Constitución, se mantiene en vigencia el actual Régimen y Organización municipal de la República». Esto equivale, ni más ni menos, a decir: he aquí el Régimen municipal de una democracia nueva, pero por ahora sigue vigente el esquema municipal de la dictadura. En esta forma la Constitución reguló un Municipio inexistente, pues, tal como allí se prevé, ni ha existido ni existe en la actualidad. Cierta- 
mente que con diecisiete años de retraso se sancionó la Ley Orgánica de Régimen Municipal de 1978, pero en la misma, aparte de desarrollarse principios de organización formal de los Municipios, no se estableció realmente el Municipio democrático como unidad política primaria y autónoma dentro de la organización nacional, sino que mediante normas transitorias, repetida en 1984, en la propia Ley se reafirmó la transitoriedad del antiguo Régimen municipal. De nuevo nos encontramos aquí la contrariedad consensual de la Constitución de prever una institución que la propia Constitución impide aplicarla de inmediato, mediante un régimen transitorio.

En definitiva, por las sucesivas transitoriedades, aún no se ha establecido el Municipio previsto en la Constitución. Ese Municipio del que hablan los artículos 25 y siguientes del Texto fundamental no existe, y, a lo sumo, lo que todavía seguimos teniendo es el Distrito autónomo, siguiendo el esquema que se estableció en 1904.

En esta forma, uno de los efectos políticos de la voluntad de mantener el régimen democrático, como desiderátum del Pacto de Punto Fijo, además del sistema de partidos, es el sistema de Estado centralizado concebido en la Constitución, de manera tal que fortaleciéndose el Poder nacional se producía un debilitamiento de los Estados, y si bien se creó el Poder municipal, se suspendió la vigencia de las normas constitucionales que lo regulaban para mantener el centralismo.

\section{EL RETO DE LA DESCENTRALIZACION PARA PERFECCIONAR LA DEMOCRACIA: EL NUEVO FEDERALISMO}

\section{Centralización y Federación}

De lo dicho anteriormente resulta que el Estado venezolano contemporáneo es Estado centralista y centralizador, consolidado al amparo del texto constitucional de 1961, el cual, sin duda, también es una Constitución centralista.

Ahora bien, hablar de Federación exige aclarar el contenido de este término político-estatal, tan lleno aún de confusiones en muchas esclarecidas mentalidades contemporáneas. Ciertamente que, como se dijo, la Federación está intimamente ligada a nuestra historia como realidad política: se instauró en la Primera República en 1811; acompañó el nacimiento de la Venezuela separada de la 
Gran Colombia de 1830 a 1857; en su nombre se libraron las guerras federales y guió la estructuración de la forma de Estado a los vencedores en 1864; sirvió durante la segunda mitad del siglo pasado para consolidar el poder de los caudillos, y durante la primera mitad de este siglo para liquidarlos; y cuando se integró el país en todos los órdenes, fue relegada progresivamente. Hablar de Federación, por tanto, provoca la evocación de tantas etapas de nuestra historia, a las cuales ha estado ligada, que exige una elemental aclaratoria de lo que este término significa, sobre todo cuando el propio texto constitucional vigente declara solemnemente en su artículo 2..$^{\circ}$ que el Estado venezolano es un Estado Federal.

Federación, en efecto, es una forma de Estado descentralizado, contraria a la del Estado unitario y que reconoce la existencia de entidades políticas territoriales, con potestades políticas autónomas, reflejadas básicamente en la elección de sus autoridades, y en la existencia en ellas, de potestades públicas diversas: potestades legislativas, tributarias, administrativas y financieras autónomas. Así, un Estado será Federal si está descentralizado político-territorialmente, y será unitario si carece de entidades políticas autónomas en su territorio a niveles superiores a los municipales.

Teniendo en cuenta esto, sin duda, la forma del Estado venezolano consagrada en la Constitución es absolutamente contradictoria: nuestra Federación es centralizada, lo que conduce a la estructuración de un Estado centralizado con membrete federal. Esta contradicción ha provocado reacciones violentas en los estudios de nuestras estructuras políticas: unos, acordándose de las anécdotas históricas, propugnan la eliminación de todo vestigio federal de nuestras instituciones y que el Estado debe centralizarse totalmente; y otros, al contrario, propugnan la descentralización política del Estado como única vía futura para el logro del desarrollo político del país. Parecerá mentira, pero ciento cincuenta años después de la discusión centralismo-federación que signó al nacimiento de la República, el problema sigue planteado, pero, por supuesto, con contenido diferente.

Queremos insistir en el tema de la centralización político-administrativa de las instituciones venezolanas y sus efectos para plantear cuál es el sentido de una de las transformaciones que, en nuestro criterio, está exigiendo nuestro sistema institucional.

En efecto, como hemos señalado, el Estado venezolano es un Estado centralizado, porque el poder político, jurídico, financiero, 
tributario, normativo y administrativo básicamente reposa en las instituciones políticas nacionales: el Congreso y el Poder Ejecutivo. De resultas, el país, fuera de la sede de los Poderes nacionales, existe con dificultad, siendo la vida política de nuestras Provincias inocua e inútil: no sirve para nada, salvo para la supervivencia de los lideres políticos locales, los cuales, en general, tienen una sola mira: Caracas. El interior, políticamente, no atrae; al contrario, espanta, y sólo los hombres con espíritu de conquista o en el otro extremo, de conformismo, se aventuran a vivir la política interiorana.

La centralización, en todo caso, se ha realizado a costa de los Estados de nuestra Federación, que han sido vaciados de contenido al quitárseles sucesivamente sus competencias. Por ello, en el momento actual, $¿$ de qué sirve entonces una Asamblea Legislativa si no tiene materia sobre la cual legislar, y de qué sirve un Gobernador, salvo de ser agente del Poder central, si no tiene materia propia estadal para administrar y gobernar? El Gobernador, por tanto, en general, gobierna materias prestadas por el Poder central, que las Asambleas Legislativas nó controlan, y éstas legislan sobre aspectos formales que no tienen nada que ver con el desarrollo económico, social y físico de los Estados.

Por otra parte, como hemos visto, a pesar de la competencia residual de los Estados, éstos no tienen recursos tributarios propios. Sus recursos financieros son dados por el Poder nacional, y como el Situado constitucional aumentó, al aumentar los ingresos ordinarios nacionales, el Estado centralista controló aún más la disposición de dichos ingresos estadales, para lo cual dictó en 1974 una de las leyes más centralizadoras de los últimos años: la «Ley de coordinación de la inversión del Situado constitucional con los planes desarrollados por el Poder nacional», con la cual se ha lesionado la poca autonomía que la Constitución consagra a favor de los Estados.

En la mentalidad simple de algunos burócratas nacionales surge entonces la excusa para no descentralizar: como no existe capacidad administrativa en la Provincia, no se puede transferir poderes de administración a las Regiones. Sin embargo, no captan el círculo vicioso que se ha armado y que es necesario romper: no hay capacidad administrativa en las Regiones precisamente porque no se descentraliza; y frente a la centralización administrativa nacional algunos pretenden que existan mecanismos de descentralización efectivos cuando se crean las Corporaciones de Desarrollo Re- 
gional, no percatándose que, en realidad, éstos son instrumentos del Poder nacional, que en algunos casos han conducido a una mayor centralización administrativa, pues en su conducción no participan las administraciones ni los gobiernos estadales. Es más, la experiencia ha demostrado en algunas de las Regiones en las cuales existen estas Corporaciones que han actuado de espaldas e ignorando a los Gobernadores de los Estados.

En el campo administrativo, por otra parte, debe insistirse en el efecto centralizador de la mencionada Ley de Coordinación del Situado con planes administrativos desarrollados por el Poder nacional. En la práctica, lejos de ser una Ley que haya conducido a la coordinación, lo que ha provocado es la imposición a los Estados de una voluntad administrativa nacional. Los Estados, en realidad, no participan en la elaboración de los programas a coordinarse, sino que bien es sabido cómo les son impuestos a los Gobernadores y a las Asambleas Legislativas.

Todo ese panorama centralizador, política y administrativamente hablando, el cual se ha desarrollado bajo el marco del Texto constitucional de 1961, como resultado ha provocado en estos últimos veinticuatro años la asfixia del interior del país. Insistimos: la administración regional no existe, lo que hay son tentáculos nacionales que penetran en los Estados; y la política estadal, si bien existe, no tiene materia ni sustancia sobre la cual actuar y moldear.

Estimamos, por tanto, que estabilizado el Estado democrático como resultado de la aplicación de la Constitución de 1961 durante las últimas dos décadas, ha llegado el momento de confiar más en el conjunto de Regiones y Estados del país para la atención de sus: propios asuntos, transfiriéndoles competencias y poderes, para lo cual debe descentralizarse, política y administrativamente hablando, el Estado venezolano. En esta descentralización necesaria es donde se sitúa el nuevo Federalismo que debe desarrollarse en el país y que se ha venido propugnando en los últimos años.

\section{Los PROBLEMAS DEL CENTRALISMO: UN FENÓMENO UNIVERSAL}

En todo caso, debe señalarse que el problema del centralismo y las exigencias de descentralización política no sólo son propios de las Federaciones como la nuestra, sino que también los encontramos en los Estados unitarios contemporáneos. En efecto, puede decirse que el esquema del Estado nacional centralizado, sea como 
forma federal o unitaria, en el momento actual de la evolución política de las sociedades contemporáneas, ya cumplió su papel. En la actualidad es un esquema en crisis que no satisface las exigencias crecientes de participación política en una democracia pluralista de las diversas comunidades de un país, y que por el desarrollo de las sociedades contemporáneas ya no es un sistema administrativamente eficiente para permitir la satisfacción de las necesidades colectivas y la prestación de los servicios públicos en forma adecuada a las exigencias sociales crecientes.

Política y administrativamente, por tanto, el Estado nacional centralizado está en crisis, y las experiencias políticas comparadas muestran esfuerzos de descentralización política como nuevas formas de organización del poder político que sustituyan a las clásicas del siglo pasado.

En efecto, durante años la teoría constitucional ha enseñado al estudiar la organización vertical del Poder que las formas clásicas de Estado son las del Estado unitario y las del Estado federal, basadas en la diferencia fundamental de que en el primer esquema existe un sistema único de instituciones políticas constituyentes y de gobierno, y, en cambio, que en el segundo esquema existe un sistema de múltiples entidades políticas, constituyentes y de gobierno autónomas. Esta dicotomía clásica puede decirse, sin embargo, que no ha existido nunca en la práctica con criterios y fronteras definidoras precisas. Así, puede decirse que nunca ha existido un Estado unitario puro sin alguna forma de Entes descentralizados, ni ha existido un Estado federal puro completamente descentralizado. La crisis del Estado nacional centralizado ha provocado por ello la crisis, tanto de las formas clásicas de Estado unitario como del Estado federal, pues ambas han sido el soporte de aquél.

Esta crisis de las formas clásicas de Estado se evidencia en el doble proceso contradictorio que en ellos se ha operado: el Estado unitario tiende cada vez más a descentralizarse, pero sin llegar al esquema ideal e inexistente del Federalismo clásico; y el Estado federal se ha caracterizado por un creciente proceso de centralismo, sin llegar tampoco al extremo del Estado unitario y comenzando a regresar ahora hacia nuevas formas descentralizadoras. En todo caso, en toda organización política se operan estas dos fuerzas y movimientos centrípetos y centrífugos, que en cada país, y de acuerdo a las realidades históricas, económicas y sociales, provocan la llegada a un punto de equilibrio. Por ello puede decirse que el signo 
contemporáneo de la evolución del Estado es el de una convergencia hacia soluciones de organización política descentralizadas similares: los Estados unitarios tienden a regionalizarse y los federalismos, después de haberse centralizados, vuelven a seguir esquemas descentralizadores.

Por tanto, en la actualidad puede decirse que la división bipartita clásica entre Estado unitario y Estado federal no refleja categorías precisamente definidas de forma de Estado, por lo que resulta inútil, frente a nuevas formas de descentralización política de Estados tradicionalmente unitarios, plantearse la discusión de si se trata de una forma de Estado unitario descentralizado o de un Estado federal, cuando, se insiste, estos esquemas clásicos no existen en sus formas teóricas en la actualidad. Hoy hay organizaciones políticas más o menos descentralizadas como esquema de distribución del Poder en forma vertical, y dentro de esa gama, sin duda, puede resultar y resulta que Estados unitarios descentralizados a Estados regionales estén más descentralizados políticamente que viejos Estados federales hoy altamente centralizados.

En efecto, la Federación, como forma de Estado en la cual se. estructura una división vertical del Poder político, basada en Entidades territoriales autónomas (Estados miembros) con poderes. constituyentes, nació como una solución empírica y ad hoc de transacción de intereses políticos, que permitió conciliar la autonomía de las Provincias diseminadas en el extenso territorio de los Estados Unidos de Norteamérica, con las exigencias de reforzar la Unión o el Poder central, para bastarse a sí mismo en la esfera de sus funciones. La evolución posterior de esa nueva forma de Estado, intermedia entre las que eran clásicas para la época, la Confederación de Estados y el Estado unitario, se va a desarrollar en medio de un proceso político dominado por los dos movimientos políticos mencionados: el centrífugo y el centrípeto, lo cual caracteriza a todas las federaciones posteriores, como hemos dicho, a favor de las fuerzas centrípetas, provocando las federaciones centralizadas de la actualidad, con nuevas tendencias hacia la descentralización.

En efecto, a pesar de que la Federación como fórmula teórica se ha considerado como un sistema avanzado de descentralización política, en la práctica y en la realidad las federaciones contemporáneas son todas relativamente centralizadas. Por otra parte, no puede decirse que hay un solo y único tipo de Estado federal. Hoy 
por hoy la mayor parte de la superficie de la tierra está regida por Estados con forma federal y en todos ellos hay peculiaridades propias; sin embargo, quizá el signo común a todas esas estructuras federales concretas es su tendencia al centralismo, es decir, a reforzar y fortalecer políticamente los niveles federales frente a los Estados miembros. Múltiples factores han influido en este proceso de centralización de los Estados federales, y entre ellos deben destacarse los factores económicos y los políticos.

Por ejemplo, en los Estados Unidos de Norteamérica ha sido la reserva al nivel federal de fundamentales poderes de imposición e intervención en la economía y el comercio, y las restricciones impuestas a los Estados lo que ha provocado el proceso centralizador. Este, por otra parte, se ha manifestado a través de la interpretación y aplicación de la Constitución derivadas de la práctica constitucional y que ha conducido a varios principios fundamentales del Federalismo americano: la cláusula de la supremacía del derecho federal sobre el de los Estados miembros, la teoría de los poderes implícitos que ha determinado el ámbito extendido en el cual opera esa supremacía y la cláusula de comercio, cuya interpretación extensiva ha dejado en manos del nivel federal la regulación casi completa y exclusiva no sólo del comercio, sino de la economía del país. El centralismo de la Federación norteamericana, además, ha tenido sus motivaciones políticas en el fortalecimiento del Poder Ejecutivo Federal, basado sobre el sistema presidencial, precisamente en una Nación que ha juzgado y juega un papel especial en la política mundial. En el Canadá, la Federación ha tenido también sus rasgos centralistas, basados particularmente en su forma peculiar de distribución de competencias, al atribuir al nivel federal, al contrario de la mayoría de las Federaciones, las competencias residuales.

En Alemania, a pesar de la distribución formal de competencias entre el nivel federal y los Länder, que coloca competencias residuales en este último nivel, la tendencia centralizadora ha conducido a una posición predominante del Bund sobre los Länder, tanto en materia económica como legislativa, y al desarrollo de competencias federales implícitas basadas, no en la figura norteamericana de los poderes implícitos, sino en razón de «la naturaleza de la materia». Igual tendencia centralizadora se observa en la Confederación suiza, que en realidad es un Estado federal, mediante el desarrollo de poderes implícitos en la Confederación derivados de in- 
terpretaciones del texto constitucional, así como de la acumulación de poderes económicos constituyen el nivel federal.

Esta tendencia centralizadora de las Federaciones se acentúa en el caso de Austria, en cuya Constitución aparece, originalmente, la figura de un "federalismo limitado" o "federalismo unitario", en el cual la Federación tiene una posición predominante al resultar favorecida por el reparto de competencias con la reserva íntegra de las potestades jurisdiccionales.

Las Federaciones latinoamericanas, en grado importante, han sufrido este proceso centralizador, y por ello, con razón, se ha hablado de las «Federaciones centralizadas de América latina». La. tendencia centralista ha conducido así a una preponderancia del Poder central en todas las Federaciones latinoamericanas sobre los. Estados miembros. Se habla así, en Argentina, de «avasallamiento de las autonomías provinciales» por el Gobierno central; de la «preeminencia evidente de la Federación» en el Estado brasileiro, que lo asemeja más a un Estado unitario descentralizado a pesar de la tradición federalista; y de la incrustación de elementos centralizadores dentro de la estructura federal del Estado mejicano como signo de centralización en la cual el factor económico ha sido. de importancia primordial.

Pero la tendencia al centralismo también ha sido un signo característico de las Federaciones socialistas. En todo estos países, la importancia política de la economía ha dado origen al principio. del centralismo democrático como principio organizativo socialista. y que, reconociendo la diversidad de Regiones de un país, permite el desarrollo organizado y centralizado de la economía planificada. en el marco de toda la Nación. Las Federaciones de la URSS, Checoslovaquia y Yugoslavia, así, obedecen a esta característica centralizada, derivada del mencionado principio del centralismo demo. crático. A ello debe agregarse, como agente centralizador, el sistema de partido único, cuya organización centralizada contrabalancea las. libertades conferidas a las entidades federales.

De lo anteriormente señalado resulta evidente entonces que la. Federación clásica no existe y quizá no existió nunca en ninguna. parte del mundo. Por eso se ha afirmado, con razón, que «el Federalismo de viejo estilo ha muerto" y en su lugar han surgido formas de distribución vertical del poder con ropaje federal, pero que aproximan los Estados federales a las fórmulas de los Estados unitarios descentralizados. 
En muchos casos, la tendencia a la centralización de las Federaciones ha dado origen a un "federalismo de cooperación" o "federalismo cooperativo", conforme al cual tanto la Federación como los Estados miembros asumen tareas en común. Se trata, por tanto, de la quiebra del sistema tradicional de reparto de competencias, sustituida por un sistema de colaboración o co-participación del nivel federal y los Estados miembros en la realización de unas mismas tareas públicas en forma concurrente o conjunta.

Esta fórmula de Federalismo coordinado, compartido o cooperativo, que da origen a relaciones intergubernamentales dinámicas, es quizá hoy el signo más característico de las Federaciones contemporáneas, luego de haber sufrido el proceso centralizador que les es común. En la consolidación en este sistema de cooperación es, quizá, donde está la clave para la nueva descentralización que se está tratando de realizar en las Federaciones y así lograrse el equilibrio deseado entre las fuerzas centrífugas y centrípetas en la organización del Estado.

Pero el juego de estas fuerzas y el proceso centralización-descentralización se ha dado también en los Estados unitarios. En éstos la tendencia ha sido la descentralización.

En efecto, así como hemos dicho que la Federación, como fórmula máxima de descentralización política, no existe, también puede afirmarse que la fórmula del Estado unitario, en el cual sólo existe un centro de poder y de gobierno, tampoco existe.

El Estado unitario se estructuró, ciertamente, con el nacimiento del Estado moderno y se consolidó con la Revolución Francesa, en la cual la centralización fue el instrumento para la destrucción de los cuerpos intermedios y los privilegios y, a la vez, el medio para el mantenimiento en el poder de la burguesía.

Sin embargo, a medida que se fue democratizando la democracia, la democracia pluralista transformó los viejos Estados unitarios, pues provocó el surgimiento de niveles inferiores de poder a nivel local; la democracia implicó así la descentralización en los Estados unitarios, por lo que en éstos se puede distinguir siempre un grado de descentralización local, en el sentido de la exigencia de colectividades político-territoriales menores: Municipios o Comunas con autonomía político-territorial.

Pero las propias exigencias de la democracia pluralista han provocado la necesidad de establecer un sistema político o forma de Estado que acerque más las instituciones políticas a los ciudada- 
nos y asegure la participación democrática en varios niveles territoriales y no sólo en el nivel local. Asimismo, la satisfacción de las. necesidades colectivas en sociedades industrializadas y urbanas. complejas ha mostrado la insuficiencia del Estado centralizado para actuar adecuadamente en todo el territorio. De allí que haya sido. una tendencia general, en todos los Estados unitarios, la aparición de niveles intermedios desconcentrados (Regiones o Departamentos) para la acción nacional y resolución de los asuntos públicos. Inicialmente se ha tratado de un proceso económico o administrativo (regionalización económica y administrativa) y progresivamente se ha venido convirtiendo en un proceso político.

Por ello, el signo contemporáneo de los Estados unitarios es el de su regionalización política, dando origen a una nueva forma de Estado que comienza a delinearse: la del Estado regional, como una forma más o menos avanzada de descentralización, caracterizado por el hecho de que, además del nivel nacional, conserva el poder constituyente único, y del nivel local (municipal), han surgido unidades político-territoriales autónomas intermedias, producto de la descentralización política con autonomía territorial. Estas unidades territoriales intermedias se caracterizan por tener una autonomía política con potestad legislativa regional, cuyos órganos. son electos por votación popular, materializándose la democracia regional. Ha sido conforme a estos esquemas que se han producido las reformas políticas de distribución vertical del Poder en Italia con el Estado regional; en Bélgica, con el Estado de Comunidades y Regiones; en España, con el Estado de Comunidades Autónomas, y en Francia, con su reciente regionalización política.

\section{El nuevo Federalismo}

Por tanto, hablar de descentralización política es hablar de un movimiento contemporáneo que ha tocado a casi todos los Estados. del globo, sea con forma de Estados unitarios o Estados federales. Por supuesto, la Federación no es precisamente una fórmula nueva de descentralización; sin embargo, si ella existe, así sea en el papel, como en Venezuela, no tendría sentido buscar otras formas de descentralización política autonómica como las mencionadas, que comienzan a evidenciarse como nuevas formas de Federalismo. Por ello, insistimos en partir de la fórmula federal para propugnar la 
descentralización político-administrativa del Estado, para lo cual la Federación debe revitalizarse.

Esta revitalización, por supuesto, puede comenzar dentro de los. marcos de la Constitución vigente. No se olvide que ésta permite al Poder nacional transferir a los Estados y Municipios materias de la competencia nacional a fin de promover la descentralización. administrativa (art. 137), lo cual aún no ha ocurrido en ningún caso. Además, la revitalización del Federalismo también puede comenzar a nivel de los propios Estados, a pesar de la inacción y oposición, en ciertos casos, de algunos niveles nacionales a quienes les aterra perder algo de su órbita de poder transfiriéndolo a las entidades estadales. Allí está el ejemplo de las reformas constitucionales de los. Estados Yaracuy, Aragua y Nueva Esparta, en las cuales tuvimos el privilegio de colaborar, las cuales han iniciado un proceso difícil. pero esperanzador por reforzar las estructuras estadales, a pesar de haber contado con la lamentable oposición abierta o subterránea. del Poder central.

En todo caso, una efectiva descentralización político-administrativa del Estado venezolano, sin duda, requerirá de una modificación sustancial de nuestro sistema institucional mediante una Enmienda constitucional que reformule el esquema de nuestra forma de Estado y establezca un Estado descentralizado tomando como base la Federación. Esta modificación constitucional debería hacer de los Estados, sea que éstos conserven en el futuro el actual ámbito territorial que tienen o éste sea modificado, auténticas entidades políticas autónomas, para lo cual habría que reformular íntegramente el sistema de distribución de competencias que los artículos 17, 30 y 136 de la Constitución actualmente atribuyen a los niveles estadales, municipales, nacionales, respectivamente.

La autonomía política, tributaria, financiera y administrativa de los Entes territoriales, en cualquier sistema de descentralización político-territorial, está directamente relacionada con el sistema de distribución de competencias que se establezca. La autonomía será inútil e inocua, en el caso de Venezuela, si no se tiene materia sobre la cual ejercerla. ¿De qué sirve que los Estados tengan autonomía tributaria si todas las materias imponibles las ha reservado la Constitución al Poder nacional o al ámbito local? ¿De qué sirve que los Estados tengan una autonomía financiera y administrativa si el crédito público y la inversión del Situado constitucional depende de lo que disponga centralizadamente el Poder nacional? En fin, ¿para 
qué sirve la autonomía política si el órgano ejecutivo de los Estados no puede elegirse por la comunidad regional, y si bien los Diputados a las Asambleas Legislativas son electos, éstos en su actividad no tienen realmente nada útil que hacer por la ausencia de com. petencias estadales y el otro corto período de sus sesiones?

Frente a este panorama desolador estimamos que la reforma del Estado para su descentralización es el reto más importante en el momento actual para lograr nuestro desarrollo político, para lo cual debemos establecer un auténtico sistema de descentralización político-administrativa del Estado, aprovechando la estructura federal que nos pertenece por tradición, para construir el Estado por dentro, revitalizando la política y la administración regional, lo que estimamos es lo más conveniente.

Transcurridos veinticuatro años de vigencia de la Constitución, ya no es posible soslayar la discusión sobre centralismo o descentralización, pues la mezcla constitucional está conduciendo al inmovilismo y a la ineficiencia total en el interior del país. Una reforma del Estado debe ser emprendida y ésa es la planteada para descentralizar al Estado, pues estimamos que en la descentralización política y administrativa del Estado venezolano es que está la clave del funcionamiento adecuado de nuestras instituciones en el futuro para que sirvan de auténticos instrumentos de desarrollo no sólo económico-social, sino político y administrativo, y como medio de perfeccionar la democracia. He allí el más grande reto y programa para una reforma del Estado.

Sin embargo, esta reforma, como cualquier otra que incida en el Estado, toca el problema del Poder. Desmontar el centralismo, hacer un nuevo Federalismo, establecer el Régimen local implica distribuir el Poder en sentido vertical, lo que significa pérdida de áreas de poder por parte de los niveles centrales-nacionales del Estado, en beneficio de las Provincias y Comunidades; y, por supuesto, pérdida de áreas de poder de los partidos políticos, a su vez configurados bajo el esquema del centralismo democrático, y quienes hasta ahora han tenido el monopolio de la participación y representatividad democrática. He allí la dificultad: desmontar el centralismo en nuestro sistema democrático sólo puede ser obra de los partidos políticos. 


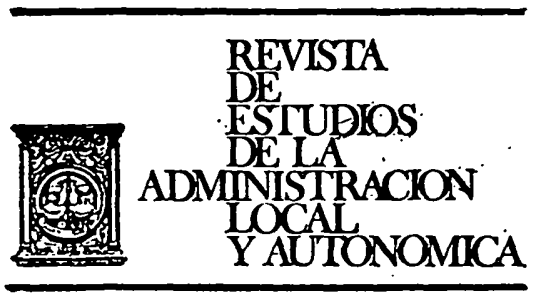

\section{CRONICAS}


REALA-1985, núm. 228. BREWER-CARIAS, ALLAN-RANDOLPH. EL DESARROLLO INSTITUCIONAL...

REALA-1985, núm. 228. BREWER-CARIAS, ALLAN-RANDOLPH. EL DESARROLLO INSTITUCIONAL... 